\title{
Mechanical Behavior of Steel Fiber Reinforced Concrete Investigated by One-Stage Light Gas Gun Experiment
}

\author{
Guoping Jiang ${ }^{1,2}$ and Xinhong $W \mathbf{u}^{2}$ \\ ${ }^{1}$ School of Engineering, Fujian Jiangxia University, Fuzhou, Fujian 350108, China \\ ${ }^{2}$ China Hydropower Eight Innings Base Station, Changsha, Hunan 410082, China \\ Correspondence should be addressed to Guoping Jiang; lp2002999@126.com
}

Received 23 May 2013; Revised 29 July 2013; Accepted 1 August 2013

Academic Editor: Peter Majewski

Copyright (c) 2013 G. Jiang and X. Wu. This is an open access article distributed under the Creative Commons Attribution License, which permits unrestricted use, distribution, and reproduction in any medium, provided the original work is properly cited.

\begin{abstract}
This paper presents shock Hugoniot compression data for several concrete materials obtained from flat plate impact experiments. The manganin pressure gauge was used to measure the pressure-time curves of the samples. The physical quantities were all obtained by the Lagrange method. Moreover, it is observed from the measured pressure-time curves that the rate sensitivity of the dynamic response to the concrete is not negligible. Based on the polynomial Grüneisen equation, the parameters of the equation of state of concrete were obtained. The steel fiber reinforcement effect was analyzed.
\end{abstract}

\section{Introduction}

Steel fiber reinforced concrete (SFRC) is one of the main structural materials widely used in industry and civil buildings. Plain concrete is a brittle material which has a low strain capacity and tensile strength. The discontinuous steel fibers distributed randomly have the role of bridging across the cracks which might develop, and they provide some post cracking "ductility." In particular, SFRC has been widely used in the construction of protective structures such as protective shelters, offshore structures, containments, and nuclear reactors. It may be subjected to loadings such as earthquake, blast loading. For reliable design and modelling of SFRC structures subjected to impact loadings, it is imperative and critical to understand the dynamic properties of SFRC.

The two most used setups to study the dynamic behavior of concrete are the Split-Hopkinson pressure bar (SHPB) and the one-stage light gas gun. The dynamic behavior of concrete-like materials at strain rates between $10^{1}$ and $10^{2} \mathrm{~s}^{-1}$ is often studied in the SHPB experiment, while at high strain rates between $10^{3}$ and $10^{5} \mathrm{~s}^{-1}$, the behavior is often studied in the one-stage light gas gun experiment $[1,2]$. The high pressure equation of state is often investigated by the one-stage light gas gun experiment because the nonlinear pressuredensity curve usually cannot be obtained with the range of the strain rate in SHPB experiments. With strain rates of $2 \times 10^{-4} / \mathrm{s}$ and $8 \times 10^{-6} / \mathrm{s}$, compressive tests of concrete were firstly carried out by Abrams (1917) [3]. Since then, the study of the dynamic mechanical properties of concrete has been a focus of many researchers. The equation of state (EOS, Hugoniot) properties of concrete are determined with two independent and different shock compression experiments by Gebbeken et al. [1]. A number of experimental data from the SHPB experiments and the three-dimensional simulation of the specimen under transient loading are presented in the study of the dynamic performance of high strength concrete by Abdullah et al. [4]. The three-dimensional simulation of concrete under transient loading and the experiment are all studied by Grady [5], Rinehart and Welch [6], Buzaud et al. [7], Shi and Wang [8], and Shao-hua et al. [9]. The dynamic mechanical performance of SFRC is much more complicated than that of concrete. Currently, there are few studies on the mechanical performance of SFRC by plate impact experiments.

In this paper, the impact experiments of SFRC are processed by one-stage light gas gun with different strain rates. The pressure gauges are embedded in the target by which the voltage $(\mathrm{mv})$-time $(\mu \mathrm{s})$ signals are recorded. Other parameters of the material such as strain, volume, and the speed of the shock wave, are obtained using propagation theory of the shock wave. The high pressure Equation of State is investigated and the effect of steel fiber reinforcement is analyzed. 
TABLE 1: The mix proportion of concrete.

\begin{tabular}{lcccccccc}
\hline & Steel fiber (\%) & Cement (\%) & Flyash (\%) & Silica fume (\%) & $\begin{array}{c}\text { Cement-sand } \\
\text { ratio }\end{array}$ & $\begin{array}{c}\text { Water-cement } \\
\text { ratio }\end{array}$ & $\begin{array}{c}\text { Water-binder } \\
\text { ratio }\end{array}$ & $\begin{array}{c}\text { Admixture (\%) } \\
\text { V0 }\end{array}$ \\
\hline V3 & 35 & 35 & 10 & $1: 1.2$ & 0.30 & 0.165 & 5.0 \\
V5 & 5 & 55 & 35 & 10 & $1: 1.2$ & 0.30 & 0.165 & 5.5 \\
\hline
\end{tabular}

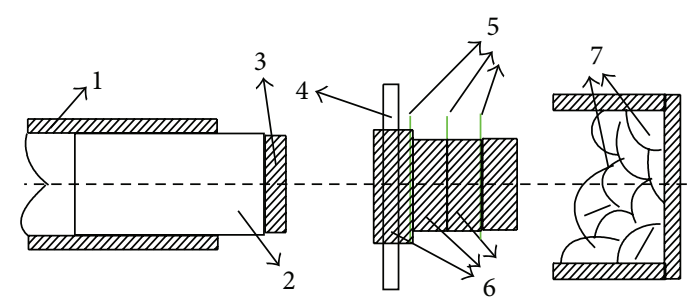
(1) Projectile assembly
(5) Base board
(2) Light chamber
(6) Managanin gauges
(3) Flyer
(4) Target
(7) Recycle bin

FIGURE 1: Setup of the experiment.

\section{Experimental Investigations}

The experiments are carried out with the one-stage light gas gun which is the main experimental setup for testing concrete. A sketch of the experiment is presented in Figure 1. The diameter of the gun is $100 \mathrm{~mm}$ and the length is $15 \mathrm{~m}$. The impact velocities are in the range of $100 \mathrm{~m} / \mathrm{s}$ to $1000 \mathrm{~m} / \mathrm{s}$. The level of impact is no more than $10^{-3} \mathrm{rad}$. The experimental strain rates range from $10^{3} / \mathrm{s}$ to $10^{5} / \mathrm{s}$. The flyer and the target are made out of the same material. The compositions of SFRC specimens are all listed in Table 1. The 425 type of Portland cement made in China is chosen. There are no aggregates used in the specimens. There are in total three gauges placed in the target to receive the impact signal. The flyer is at the front of the projectile assembly. The dimensions of the specimens are all $\phi 92 \times 8 \mathrm{~mm}$ with the aim to reduce the influence of rarefaction waves. The manganin pressure gauges record the voltage-time signals from which the pressure-time curves can be obtained through (1). The pressure-time curves are shown in Figure 2 with the same impact velocity but different fiber content $v_{f}$ (volume content of the steel fibers). They are Consider the typical curves of concrete subjected to impact loading.

$$
\begin{aligned}
\sigma= & (0.3252 \pm 0.0679) \\
& +(40.2733 \pm 0.4164)\left(\frac{\Delta R}{R}\right) \quad(1.5 \sim 12.67 \mathrm{GPa}), \\
\sigma= & (0.0014 \pm 0.0055) \\
& +(51.4697 \pm 0.2773)\left(\frac{\Delta R}{R}\right) \quad(0 \sim 1.5 \mathrm{GPa}) .
\end{aligned}
$$

As shown in Figure 2, with the same impact velocity, the load-carrying capacities of steel fiber reinforced concrete increase greatly with reinforcement ratio, as indicated by the enhancement in the peak pressure. The Lagrange positions of test concrete specimens are $0,8 \mathrm{~mm}$, and $16 \mathrm{~mm}$, respectively.

\section{Investigations Using the Lagrange Method}

The Lagrange method [10-13] is often used to investigate the dynamic performance of concrete with the gas gun experiment. The conservation equations in two dimensions are listed as follows:

$$
\begin{gathered}
u=u_{1}-\frac{1}{\rho_{0}} \int_{t_{1}}^{t_{2}}\left(\frac{l}{l_{0}}\right)^{2}\left(\frac{\partial P}{\partial h}\right)_{t} d t \\
v=v_{1}+\int_{t_{1}}^{t_{2}}\left(\frac{l}{l_{0}}\right)^{2}\left(\frac{\partial u}{\partial h}\right)_{t} d t \\
E=E_{1}-\int_{t_{1}}^{t_{2}} P(t)\left(\frac{\partial v}{\partial t}\right)_{h} d t
\end{gathered}
$$

where $\rho_{0}$ is the density, $u$ is the particle velocity, $u_{1}$ is the particle velocity of shock front, $v$ is the relatively specific volume, $v_{1}$ is the relative specific volume of shock front, $E$ is the internal energy per unit volume, $E_{1}$ is the internal energy per unit volume of shock front, and $t_{1}, t_{2}$ are the start time and end time, respectively. $h$ is the Lagrangian position, $l$ is the radial displacement, $l_{0}$ is the length of sensitive part, and $l / l_{0}$ is the relative radial displacement.

For the aim of preventing loss of the useful information in the integral along the isochrone lines, the path and trace lines are adopted in the Lagrange method investigations. The characteristic points such as the peak point of the plastic wave and the end point of elastic wave in the pressure-time curves are connected to establish the path lines.

Along the path lines and particle lines, the integral along isochrone lines changes as follows:

$$
\begin{aligned}
& \left(\frac{\partial p}{\partial h}\right)_{t}=\left(\frac{d p}{d h}\right)_{j}-\left(\frac{\partial p}{\partial t}\right)_{h}\left(\frac{d t}{d h}\right)_{j} \\
& \left(\frac{\partial u}{\partial h}\right)_{t}=\left(\frac{d u}{d h}\right)_{j}-\left(\frac{\partial u}{\partial t}\right)_{h}\left(\frac{d t}{d h}\right)_{j}
\end{aligned}
$$




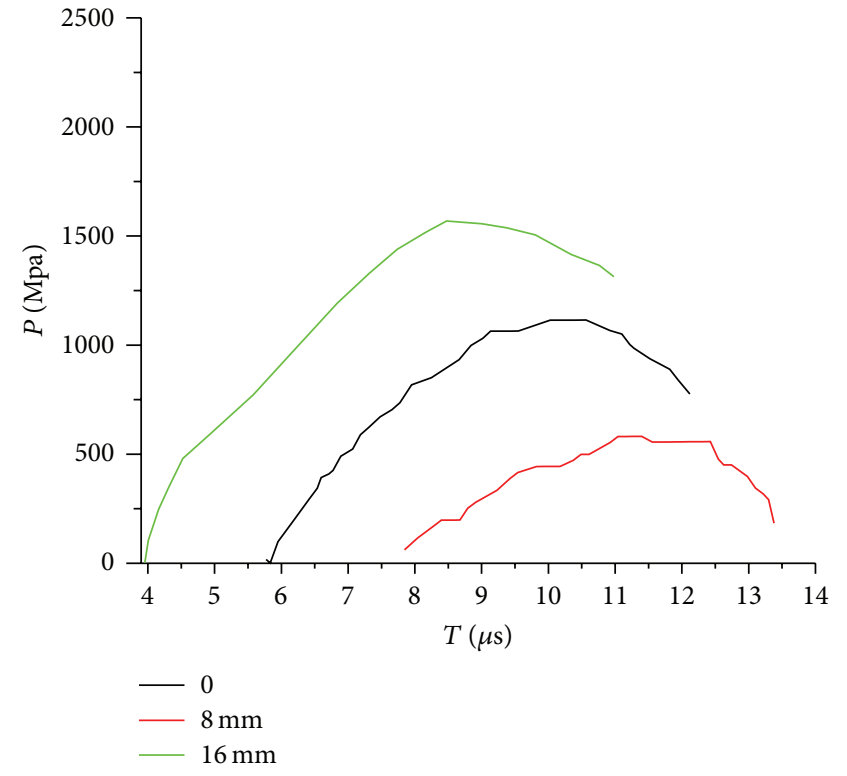

(a) $v_{f}=0$
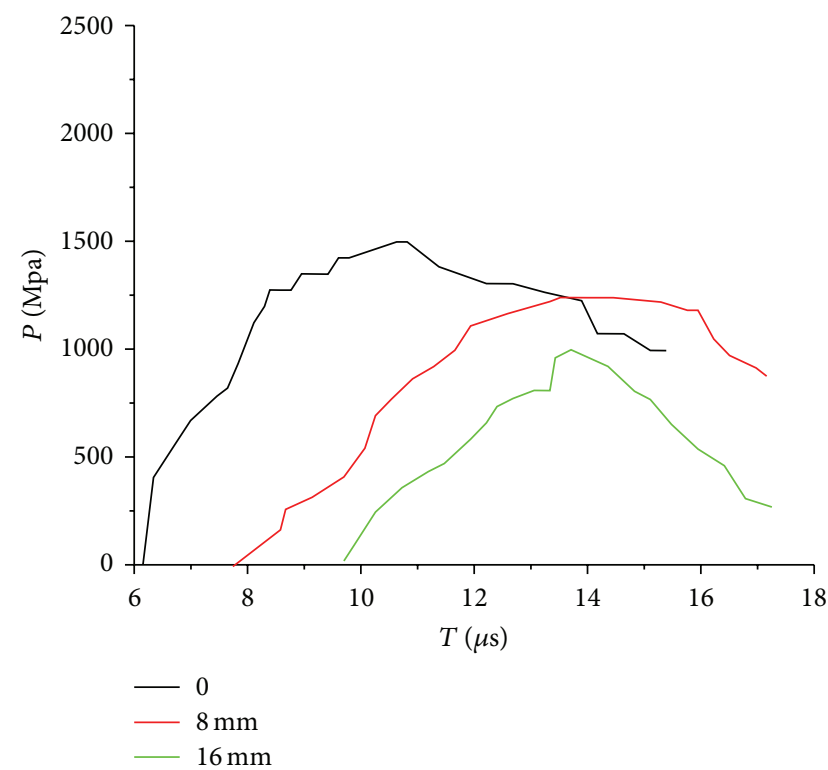

(b) $v_{f}=5 \%$

FIgURE 2: Experimental stress-time curves.

Substituting (3) into (2), we get

$$
\begin{gathered}
u=u_{1}-\frac{1}{\rho_{0}} \int_{t_{1}}^{t_{2}}\left(\frac{l}{l_{0}}\right)^{2}\left[\left(\frac{\partial P}{\partial h}\right)_{j}-\left(\frac{\partial P}{\partial t}\right)_{h}\left(\frac{\partial t}{\partial h}\right)_{j}\right] d t \\
v=v_{1}+\int_{t_{1}}^{t_{2}}\left(\frac{l}{l_{0}}\right)^{2}\left[\left(\frac{\partial u}{\partial h}\right)_{j}-\left(\frac{\partial u}{\partial t}\right)_{h}\left(\frac{\partial t}{\partial h}\right)_{j}\right] d t \\
E=E_{1}-\int_{t_{1}}^{t_{2}} P(t)\left(\frac{\partial v}{\partial t}\right)_{h} d t .
\end{gathered}
$$

The concrete $\left(v_{f}=0\right)$ is an example of the Lagrange method investigations here. The $u(t), v(t)$, and $e(t)$ curves can all be obtained from (2), with the integral along the path and trace lines of $p(t)$ curves. The strain rate can be obtained (Figure 3) from the Lagrange method.

The engineering strains are obtained (5). With (5) and the $p(t)$ curves, the relationships between strain and pressure are all obtained (Figure 4). Consider

$$
\varepsilon=\frac{\left(v_{0}-v\right)}{v_{0}} .
$$

\section{The Grüneisen EOS Investigations}

The high pressure equation of state for isotropic materials usually defines the pressure as a function of specific volume $v$ (or density, $\rho$ ) and specific internal energy $e$. Experimental shock Hugoniot relationships are widely used as reference state data extrapolating to other high-temperature thermodynamic and high-pressure states. The Grüneisen EOS is

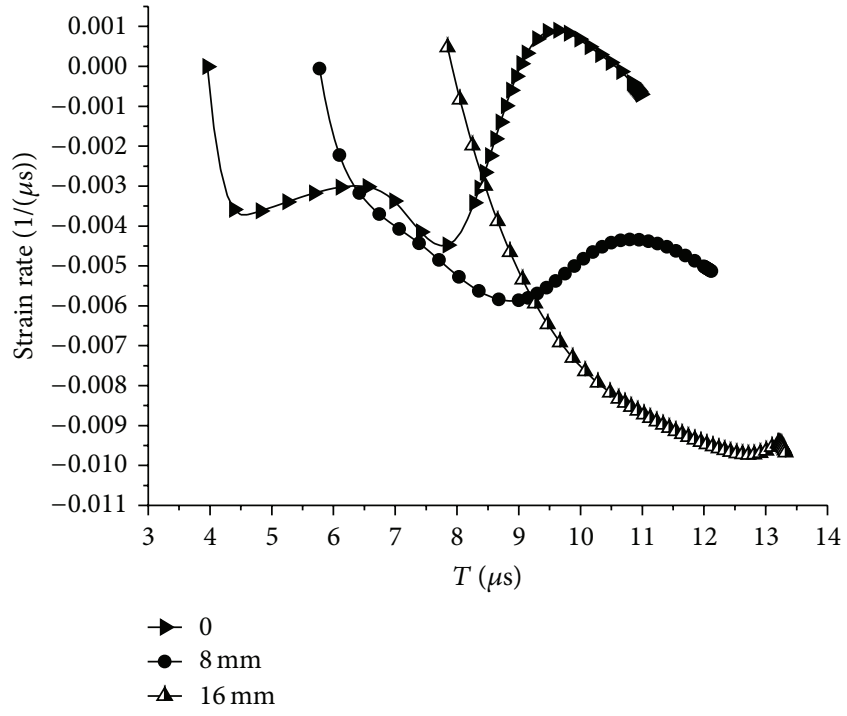

FIGURE 3: Strain rate time curves.

widely used in the constitutive model of concrete such as in Johnson-Holmquist-Concrete, Mie-Grüneisen, and Johnson-Holmquist-Ceramics.

The relationship of $P-\mu$ in Grüneisen EOS is defined as follows:

$$
P=A_{1} \mu+A_{2} \mu^{2}+A_{3} \mu^{3}
$$

where $A_{1}, A_{2}$, and $A_{3}$ are the material coefficients, $u=\rho / \rho_{0}$. Consider

$$
P=(1-\varphi) P_{s}[(1-\varphi) V, e]
$$




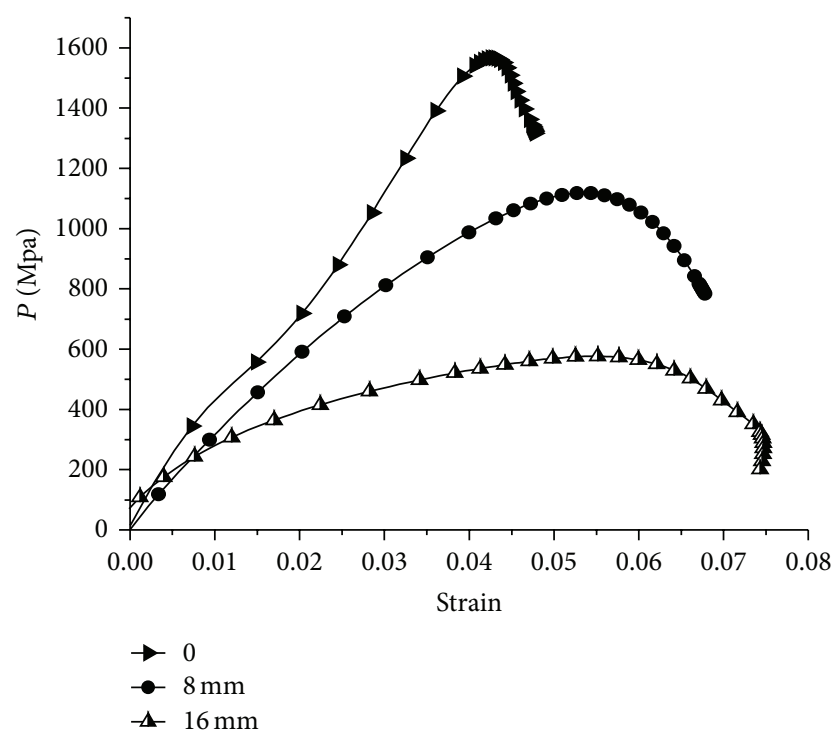

FIGURE 4: Stress-strain curves.

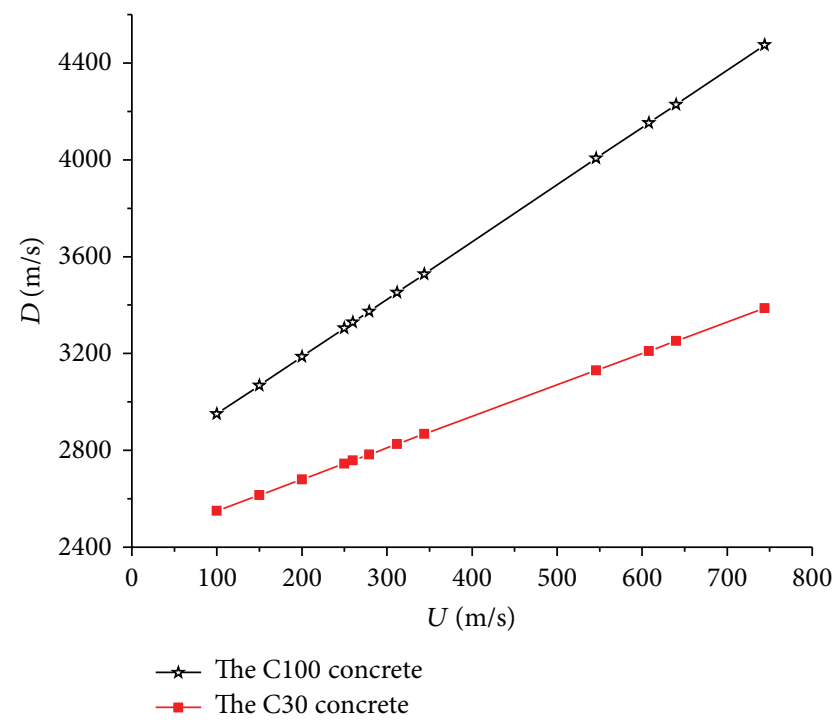

FIgURE 5: $D-U$ curves of concrete.

where $\varphi=\varphi_{0} \varepsilon^{a}\left(\varepsilon^{*}\right)^{b}, a, b$ are the material contents. $\varepsilon^{*}(=$ $\left.\stackrel{\circ}{\varepsilon} / \stackrel{\circ}{\varepsilon}_{0}\right), \stackrel{\circ}{\varepsilon}_{0}=1 / s$. With Figure 4 and (6) and (7), we can obtain

$$
A_{1}=46.4 \mathrm{GPa} ; \quad A_{2}=-195 \mathrm{GPa} ; \quad A_{3}=416.6 \mathrm{GPa} \text {. }
$$

The same method can be used to study the different steel fiber content in concrete. Consider

$$
\begin{gathered}
A_{1}=43.4 \mathrm{GPa} ; \quad A_{2}=-196 \mathrm{GPa} ; \\
A_{3}=436.6 \mathrm{GPa}, \quad v_{f}=3 \% ; \\
A_{1}=29.6 \mathrm{GPa} ; \quad A_{2}=-252 \mathrm{GPa} ; \\
A_{3}=616.6 \mathrm{GPa}, \quad v_{f}=5 \% .
\end{gathered}
$$

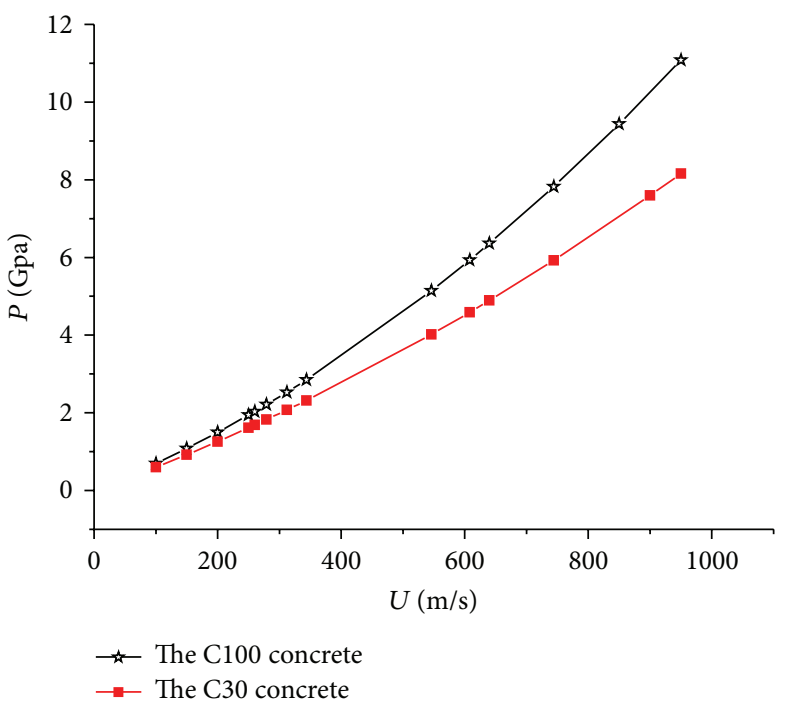

FIgURE 6: $P-U$ curves of concrete.

There is also another method which can determine the EOS. Consider

$$
U=\frac{1}{2} u
$$

where $U$ is the mass velocity and $u$ is the projectile velocity.

The relationship of the shock wave velocity $D$ and particle $U$ is often linear (Figure 5).

$$
D=a+b U
$$

where $a$ and $b$ are the material parameters. Fitting a line through the discrete points, we can obtain the $a$ and $b$ values. For C100, $a=2713, b=2.368$. For C30, $a=2420, b=1.31$. The shock wave pressure $P$ and the particle velocity $U$ have the following relationship:

$$
P=\rho D U=\rho(a+b U) U .
$$

So the $P-U$ Hugoniot curve can be obtained (Figure 6). It is noted that $P-U$ Hugoniot curve is not stress-strain relationship.

The mass conservation equation is

$$
\rho_{1}\left(D_{1}-u\right)=\rho_{2}\left(D_{2}-u\right) .
$$

Substituting (11) and (12) into (13), we get

$$
P=\frac{a^{2}\left(v_{0}-v\right)}{(b-1)^{2} v^{2}\left[b /(b-1)-v_{0} / v\right]^{2}} .
$$

The $P$ - $\mu$ curves can be calculated (Figure 7, C30 is the example). Considering (6), we get $A_{1}=19.09, A_{2}=-156.26$, and $A_{3}=999.655$ for C30 concrete. 


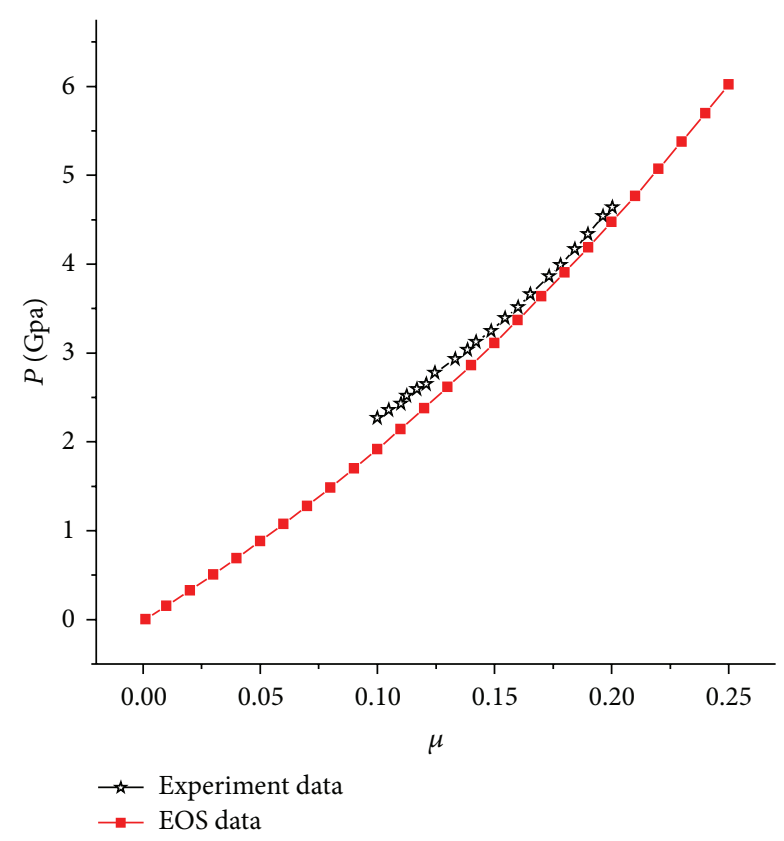

Figure 7: $P-\mu$ curve for concrete.

\section{Conclusions}

The dynamic characteristics of steel fiber reinforced concrete are very complicated. In this paper, the impact experiments of steel fiber reinforced concrete with different steel fiber ratios are processed by one-stage light gas gun. The pressure gauges are embedded in the target and the voltage-time signals are recorded. The stress-strain relationship curves are obtained by the Lagrangian method. The parameters of the equation of state are all obtained. The steel fiber reinforced effect can be seen from the Grüneisen EOS parameters. It is shown that when the steel fiber content is less than $3 \%$, the effect of the EOS is unconspicuous. When the steel fiber content is more than $3 \%$, the effect of the EOS is more conspicuous.

\section{Acknowledgments}

This work was supported by the project of China Hydropower Eight innings (20133), Housing and Urban-Rural Construction Bureau (2012-k4-17), and the Guangzhou Baiyun District Science and Technology Project (Grant no. 2012-KZ-58).

\section{References}

[1] N. Gebbeken, S. Greulich, and A. Pietzsch, "Hugoniot properties for concrete determined by full-scale detonation experiments and flyer-plate-impact tests," International Journal of Impact Engineering, vol. 32, no. 12, pp. 2017-2031, 2006.

[2] S. Pattofatto, A. Poitou, H. Tsitsiris, and H. Zhao, "A new testing method to investigate the compacting behaviour of fresh concretes under impact loading," Experimental Mechanics, vol. 46, no. 3, pp. 377-386, 2006.
[3] D. A. Abrams, "Effect of rate of application of load on the compressive strength of concrete," Journal of ASTM, vol. 17, part 2, pp. 364-377, 1917.

[4] H. Abdullah, S. Husin, H. Umar, and S. Rizal, "The dynamic properties behavior of high strength concrete under different strain rate," in $3 r$ International Conference on Experimental Mechanics and 3rd Conference of the Asian Committee on Experimental Mechanics, Proceedings of SPIE, pp. 56-59, December 2004.

[5] D. Grady, "Shock equation of state properties of concrete,' in Proceedings of the 1996 4th International Conference on Structures Under Shock and Impact IV (SUSI '96), pp. 405-414, Computational Mechanics, July 1996.

[6] E. J. Rinehart and C. R. Welch, "Material properties testing using high explosives," International Journal of Impact Engineering, vol. 17, no. 7, pp. 673-684, 1995.

[7] E. Buzaud, D. Don, S. Chapelle et al., "Perforation studies into MB50 concrete slabs," in Proceedings of the 9th international Symposium on Interaction of the Effects of Munitions with Structures, pp. 407-414, Berlin, Germany, 1999.

[8] S. Shi and L. Wang, "Discussion on dynamic mechanical behaviors of cement mortar under quasi-one and one dimensional strain states," Chinese Journal of Rock Mechanics and Engineering, vol. 20, no. 3, pp. 327-331, 2001.

[9] Y. Shao-hua, Q. Qi-hu, Z. Zao-sheng et al., "Experimental study of equation of state for high-strength concrete and highstrength fiber concrete," Journal of PLA University of Science and Technology, vol. 1, no. 6, pp. 49-53, 2000.

[10] Z. Zhang, S. Huan, and F. Lu, "Lagrangian analysis of flow field in detonation reaction zone of high explosives," Expolosion and Shock Waves, vol. 16, no. 3, pp. 271-277, 1996.

[11] N. Jiangguo, "Investigation on impact behavior of concrete," Chinese Journl of Theoretical and Applied Mechanics, vol. 38, no. 2, pp. 199-204, 2006.

[12] D. Chuen-tong, Z. Bao-ping, and J. Chun-lan, "A study on the dynamic constitutive relationship of metallic copper marking use of lagrange analysis technique," Sichuan Ordnance Journal, no. 1, pp. 54-59, 1995.

[13] H. Shi, "Consistency among reaction rate equation and state equations of solid explosive," Journal of Hunan University, vol. 30, no. 3, pp. 15-18, 2003. 

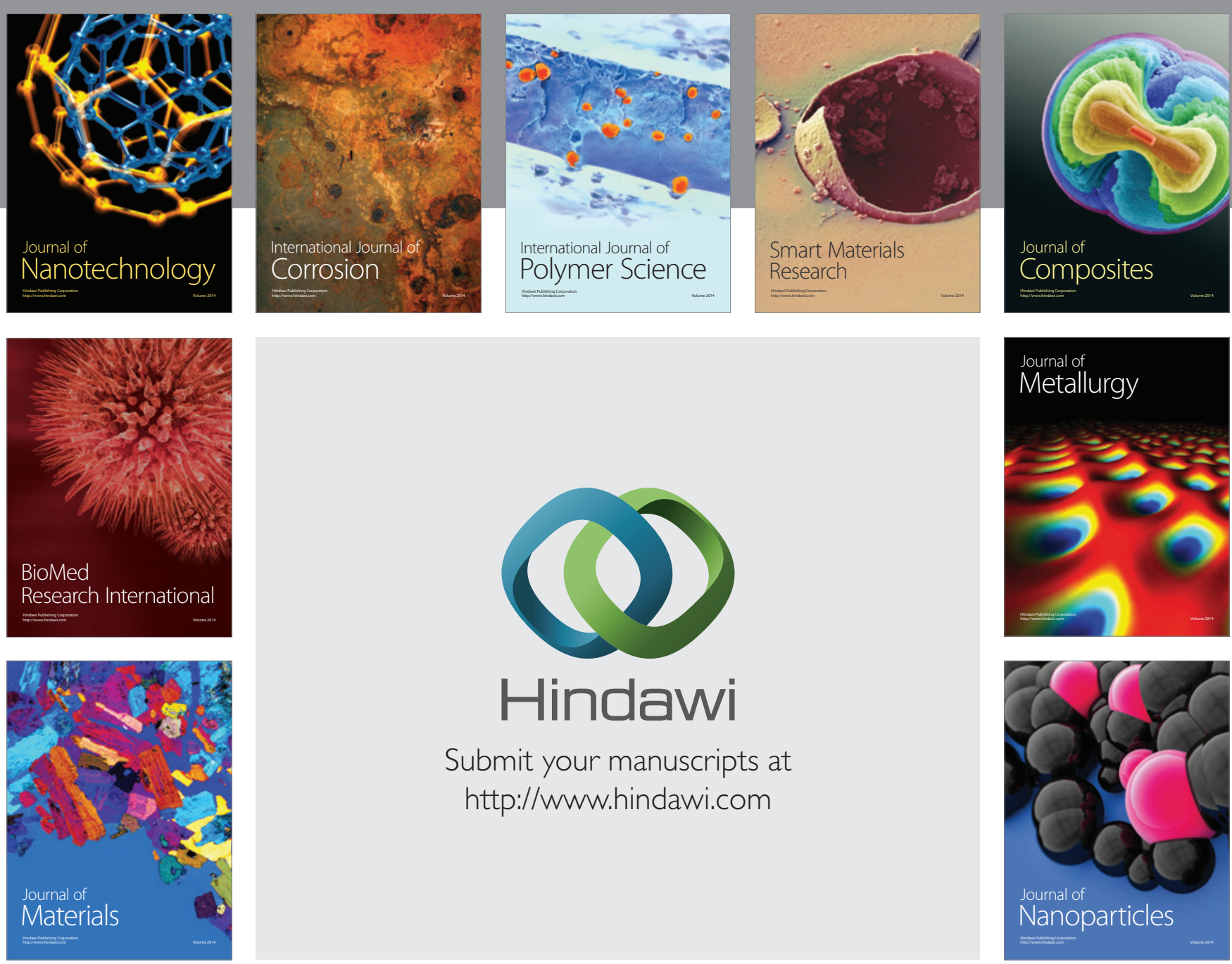

Submit your manuscripts at http://www.hindawi.com
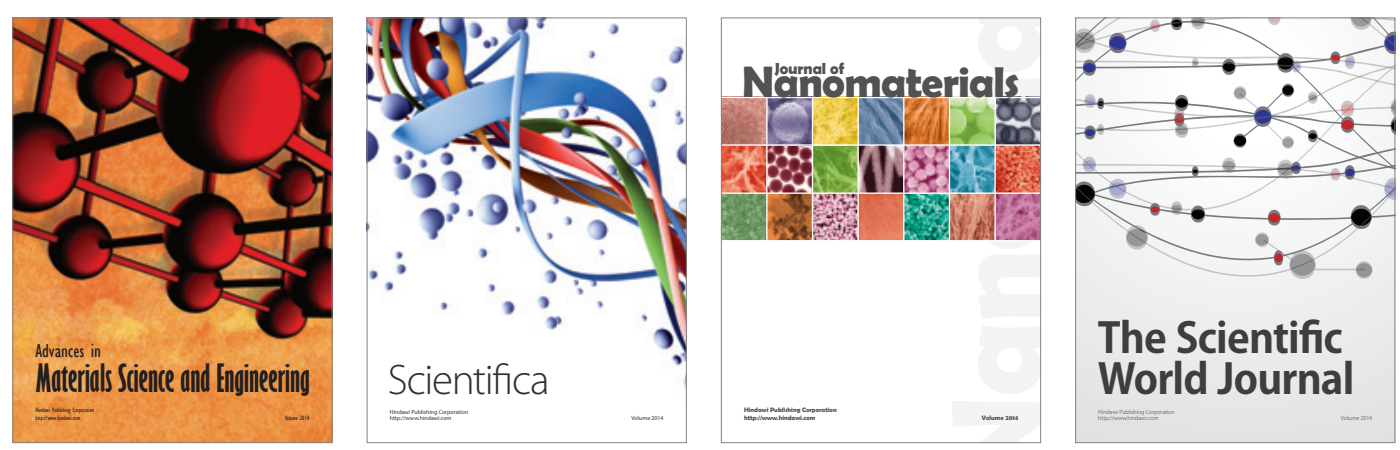

\section{The Scientific World Journal}
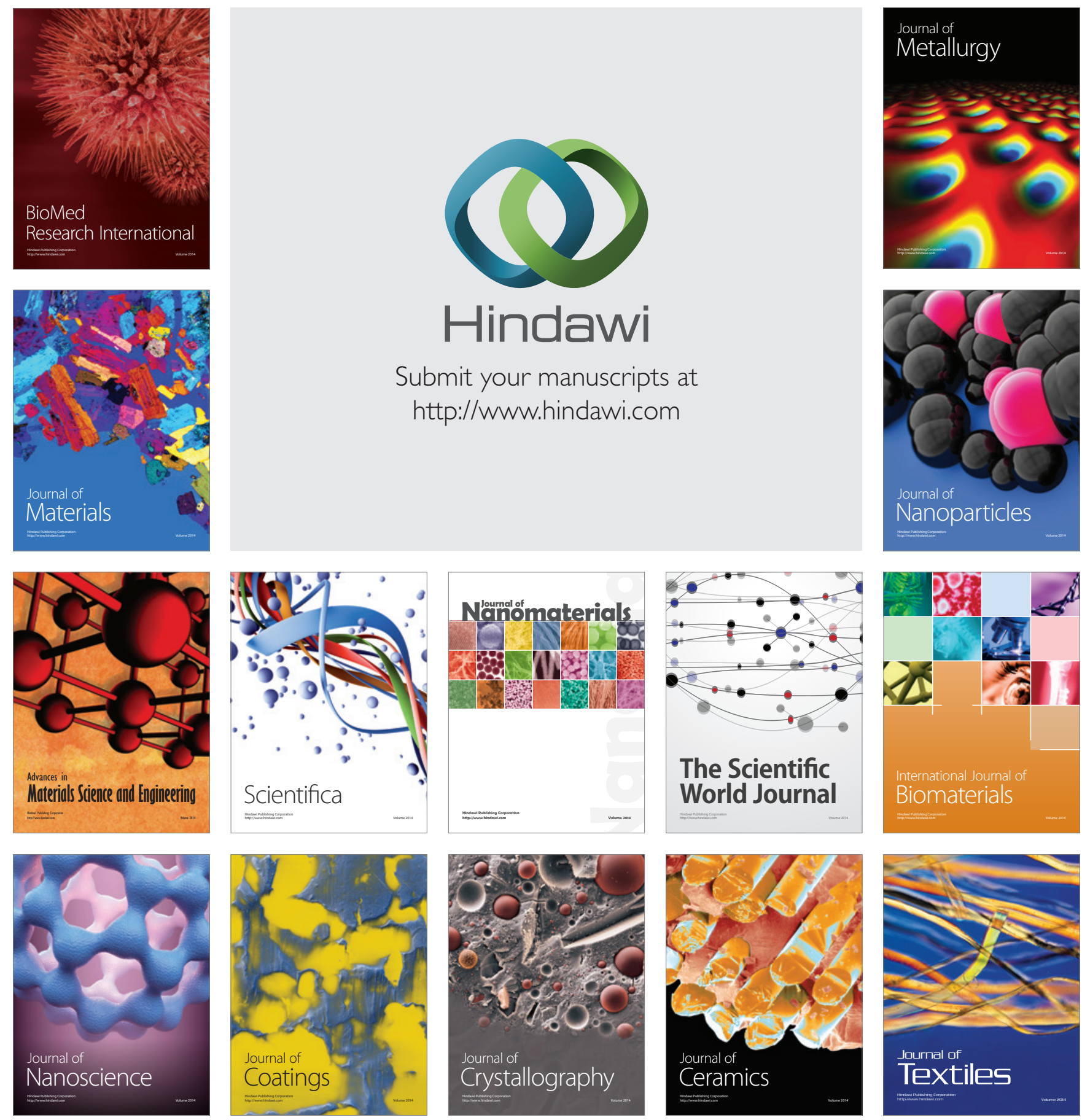